\title{
Treatment of Leprosy with Rifampicin and Isoprodian in 38 Patients at St. Thomas Hospital, Chetput, South India
}

\author{
M. ASCHHOFF \\ St Thomas Hospital and Leprosy Centre, \\ Chetput, 606801, India
}

\begin{abstract}
A clinical and bacteriological study is described of rifampicin in a dose of $300-600 \mathrm{mg}$ daily combined with Isoprodian 2-3 tablets daily in 38 patients, 30 of them lepromatous in type, and continued for periods up to 16 months. Clinical and neurological improvement was general, in some cases outstanding. Bacteriological improvement was inconstant. A rapid decline in Morphological Index to $1 \%$ or less was usual within 6 months. In some cases the decline in Bacteriological Index was outstanding, superior to that experienced in patients receiving clofazimine or high dose dapsone, but in other cases this was not so.

Side effects included mild hepatitis with jaundice in the first few weeks of treatment, which did not demand withdrawal from the trial. There was 1 case of exfoliative dermatitis, and 3 patients were withdrawn from the trial on account of severe reactions resulting in paralysis.
\end{abstract}

At our institution, engaged in field work in a rural area in South India since 1960, rifampicin was used in combination with Isoprodian and studied in 38 patients. They received $300-600 \mathrm{mg}$ rifampicin and 2-3 tablets Isoprodian daily according to their body weight. Detailed laboratory investigations carried out monthly included, ESR, haemoglobin, leucocyte and differential blood cell count, Takata, SGPT, SGOT, serum bilirubin, total serum protein, cadmium, fasting blood sugar, urine status, sputum and stool tests. Clinical assessments including chest X ray were undertaken at regular intervals. Out of 38 patients selected, 25 were males and 13 females, all in the age group 8-55 years.

Thirty patients were classified as suffering from leprosy of L type, 6 of B type, $1 \mathrm{~T}$ type in reaction, $1 \mathrm{~T}$ in a state of healing. This last patient was selected because she was 1 of 2 patients having simultaneous tuberculosis, 1 of them pulmonary, 1 of them spinal.

Thirty-two patients had had previous anti-leprosy treatment, many of them for several years, and either did not respond to it, showed signs of intolerance, or had repeated reactional episodes. They were known to us as "problem patients". Six patients assured us they had had no previous anti-leprosy treatment whatever.

* This work was undertaken in collaboration with Professor E. Freerksen, Director of the Research Institute Borstel, West Germany. 
The duration of the trial is as follows:
16 months
22 patients
15 months
7 patients
14 months
9 months
2 patients
6 months
1 patient
6 patients

Treatment had to be stopped in 5 of the 38 patients for the following reasons:

(1) One patient withdrew on her own initiative. She had an abortion, was irregular in attendance, and subsequently put on dapsone.

(2) One patient developed severe exfoliative dermatitis after 2 months' treatment and was transferred to treatment with clofazimine.

(3) Three patients experienced frequent reactions with neuritis resulting in paralysis.

Two groups of patients, only mildly bacteriologically positive at the onset of the trial, were treated as follows.

The first, consisting of 4 patients ( 2 lepromatous, 1 borderline, $1 \mathrm{~T}$ in reaction) BI 0.5 , were given the combined treatment for 6 months. By the time all were completely negative in their BI. No further treatment was given and the patients

$\therefore$ have subsequently been kept under regular observation for 9-10 months. They are all clinically without signs of activity, and skin smears continue to be negative.

The second group consisted of 3 patients of lepromatous type with BI 0.5 together with 1 patient $T$ in type with tuberculosis of the spine, and added to the trial for that reason, even though the BI was zero. The 3 lepromatous patients all became negative within 3 months of combined therapy, which was continued for a further 3 months, and then treatment was continued with dapsone $600 \mathrm{mg}$ per week. All continue in good health, with skin smears negative, though the patient with tuberculosis has been irregular in attendance for follow up.

In 2 patients, 1 of them a child of 8 years, both with lepromatous leprosy, we were anxious regarding liability to reactions, and Lamprene was added to the drug combination from the start. Clinical improvement in 6 months is considerable, and in both the MI has come down to $1 \%$ and $2 \%$ respectively. In the child the BI has fallen from 4.14 to 2.42 , but remains steady in the other (adult age 35 ) patient at 3.16 .

One patient actually in a state of reaction received rifampicin and Lamprene right from the start. After 6 months her $\mathrm{BI}$ is still 4.85 , but her MI fell to $2 \%$ within 5 months.

These small groups are the exceptions. The major group was treated and still is being treated with the combination of rifampicin and Isoprodian. In 3 out of 4 borderline cases the patients have improved considerably clinically during a treatment period of 6-15 months. Negative smears were found after 2 months in 2 patients previously treated with other drugs, and after 6 months in 1 patient receiving his first anti-leprosy treatment. The patient with pulmonary tuberculosis became sputum negative after 3 months. A fourth patient, a boy of 12 years, classified as BL also improved very well clinically, and after 1 month became smear-negative, but subsequently a few bacilli were found.

Out of the 18 patients with lepromatous leprosy, 2 of them Nos 7 and 8, who were mildly positive at the start of treatment, became negative within 1 year, 6 improved considerably within 16 months, their BI having come down from 5.0 to 1.0 or 0.5 , the MI being $0 \%$. In 9 other patients, who have been continuing 
treatment for 11-16 months, the MI is zero, but the BI shows scarcely any change as yet. One patient shows no response either in MI or BI after 6 months.

\section{Further Observations}

\section{Sensory assessment}

Fifty per cent of patients recelving the drug combination had at the onset anaesthesia to light touch to some extent in hands or feet or both. In 10 patients this had developed within the past 1-2 years, and these regained sensation at least partially, notably in the thumb-index finger web space.

\section{Regrowth of eyebrows}

Out of the 21 patients showing loss of eyebrows 8 showed moderate regrowth. One male patient aged 28 years had scanty regrowth of his beard.

\section{Muscle power}

Six patients out of 18 showed some improvement in the muscle power in the hands, confirmed by electrical studies. Here too the paresis was of recent origin, occurring within the previous 6 months to 3 years.

\section{Side-effects}

(1) Several patients showed a mild form of hepatitis with jaundice during the first few weeks of treatment, but recovered under usual care without any interruption of the rifampicin combination treatment in some cases and only very brief interruption in others.

(2) ENL and neuritis were seen and treated with thalidomide and Mogadon; 3 patients had to be withdrawn from the trial on account of repeated severe reactions resulting in paralysis (mentioned above).

(3) One patient developed exfoliative dermatitis and had to discontinue.

Anaemia, leucopenia and thrombocytopenia were not seen.

\section{Experience with Other Drugs}

\section{Lamprene}

Eight patients with lepromatous leprosy and high BI have been under Lamprene treatment for 9-27 months. In 1 of these the BI became negative after 19 months, but the others still have a BI of 2.0 or 3.0 .

\section{Lamprene followed by high dose dapsone}

Nine patients were treated with Lamprene for 1-18 months because of frequent reactional episodes and then put on DDS $600 \mathrm{mg}$ per week. No severe reaction occurred subsequently. Three patients achieved a negative BI within 18 months of starting Lamprene, 5 have improved, and 1 has remained in statu quo. 
TABLE 1

\begin{tabular}{|c|c|c|c|c|c|c|c|}
\hline Therapy forms & $\begin{array}{l}\text { List } \\
\text { No. }\end{array}$ & Name & Age & $\begin{array}{l}\text { Record } \\
\text { No. }\end{array}$ & $\begin{array}{l}\text { Pre-treatment } \\
\quad \text { (years) }\end{array}$ & Type & Bact. \\
\hline \multirow[t]{22}{*}{ Rifampicin + Isoprodian } & 1 & $\mathrm{CH}$ & 23 & $12815 / 73$ & 2 & $\mathrm{BB} / \mathrm{TBC}$ & + \\
\hline & 2 & A & 35 & $3119 / 74$ & 0.5 & $\mathrm{BB}$ & + \\
\hline & 3 & $\mathrm{D}$ & 31 & $14527 / 67$ & 5.6 & LL & + \\
\hline & 4 & $\mathrm{~K}$ & 41 & 54372 & 10.9 & LL & + \\
\hline & 5 & $\mathrm{R}$ & 20 & $7756 / 67$ & 5.5 & $\mathrm{LL}$ & + \\
\hline & 6 & $\mathrm{~S}$ & 26 & & 0.5 & $\mathrm{LL}$ & + \\
\hline & 7 & E & 15 & $4092 / 70$ & 3.2 & LL & + \\
\hline & 8 & A & 32 & $12672 / 67$ & 10.5 & LL & + \\
\hline & 9 & $\mathrm{~K}$ & 20 & $5063 / 73$ & - & $\mathrm{BL}$ & + \\
\hline & 10 & $\mathrm{~N}$ & 44 & $5255 / 69$ & 11.9 & $\mathrm{LL}$ & + \\
\hline & 11 & TS & 55 & $2187 / 72$ & 1.3 & LL & + \\
\hline & 12 & ST & 12 & $5227 / 73$ & - & B L & + \\
\hline & 13 & $\mathrm{~S}$ & 33 & $1258 / 68$ & 12.8 & LL & + \\
\hline & 14 & $\mathrm{~A}$ & 32 & $12911 / 69$ & 3.6 & LL & + \\
\hline & 15 & $\mathrm{CH}$ & 45 & $1227 / 68$ & 12.5 & LL & + \\
\hline & 16 & $\mathrm{E}$ & 19 & $7815 / 66$ & 12.6 & $\mathrm{LL}$ & + \\
\hline & 17 & $\mathrm{~N}$ & 35 & $7131 / 66$ & 6.5 & LL & + \\
\hline & 18 & I & 46 & $4071 / 67$ & 2.2 & $\mathrm{LL}$ & + \\
\hline & 19 & $\mathrm{P}$ & 46 & $1079 / 72$ & 12.7 & LL & + \\
\hline & 20 & E & 41 & $4848 / 67$ & 12.5 & LL & + \\
\hline & 21 & $\mathrm{R}$ & 8 & $1556 / 71$ & 6.3 & $\mathrm{LL}$ & + \\
\hline & 22 & M & 46 & $3667 / 74$ & - & $\mathrm{LL}$ & + \\
\hline Rifampicin + Lamprene & 1 & SH & 36 & $1856 / 74$ & 1 & LL & + \\
\hline \multirow[t]{2}{*}{ Rifampicin + Isoprodian + Lamprene } & 1 & $\mathrm{~N}$ & 8 & $2898 / 74$ & 0 & LL & + \\
\hline & 2 & M & 35 & $3037 / 74$ & $6 / 12$ & LL & + \\
\hline \multirow{4}{*}{$\begin{array}{l}\text { Rifampicin + Isoprodian } 6 \text { months } \\
\text { followed by DDS ( } 100 \mathrm{mg} \text { daily) }\end{array}$} & 1 & B & 18 & $5427 / 73$ & $10 / 12$ & LL & + \\
\hline & 2 & V & 31 & $8069 / 72$ & 1.4 & LL & + \\
\hline & 3 & $\mathbf{R}$ & 35 & $9274 / 70$ & 3.5 & LL & + \\
\hline & 4 & 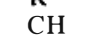 & 40 & $2130 / 73$ & $3 / 12$ & $\mathrm{TT} / \mathrm{TBC}$ & - \\
\hline Rifampicin + Isoprodian 6 months & 1 & $Y$ & 14 & $10482 / 70$ & 2.6 & LL & + \\
\hline \multirow{3}{*}{ followed by observation only } & 2 & $\mathrm{P}$ & 40 & $4178 / 70$ & 12.5 & LL & + \\
\hline & 3 & $\mathrm{R}$ & 8 & $4773 / 73$ & $1 / 12$ & BB & + \\
\hline & 4 & $\mathrm{P}$ & 30 & $9253 / 72$ & $4 / 12$ & TR & + \\
\hline
\end{tabular}


TABLE 2

\begin{tabular}{|c|c|c|c|c|c|c|c|c|c|c|c|c|c|c|c|c|}
\hline \multicolumn{17}{|c|}{ Bacteriology after months of treatment } \\
\hline 1 & 2 & 3 & 4 & 5 & 6 & 7 & 8 & 9 & 10 & 11 & 12 & 13 & 14 & 15 & 16 & 17 \\
\hline - & - & - & - & - & - & - & $(-)$ & & & & & & & & & \\
\hline+ & - & - & - & - & $(-)$ & & & & & & & & & & & \\
\hline+ & - & - & - & $(-)$ & $(-)$ & - & $(-)$ & $(-)$ & - & - & - & - & $(-)$ & & & \\
\hline+ & + & + & + & - & $(-)$ & $(-)$ & $(-)$ & $(-)$ & $(-)$ & $(-)$ & - & $(-)$ & $(-)$ & $(-)$ & & \\
\hline+ & + & + & + & $(-)$ & - & $(-)$ & - & - & - & - & - & $(-)$ & & & & \\
\hline+ & & + & + & - & - & $(-)$ & + & $(-)$ & - & - & - & - & - & $(-)$ & & \\
\hline+ & + & + & + & + & - & + & - & - & $(-)$ & $(-)$ & - & - & - & & & \\
\hline+ & + & - & + & + & - & - & + & - & - & - & - & - & - & - & & \\
\hline+ & + & + & - & + & - & + & + & - & - & - & - & $(-)$ & $(-)$ & & & \\
\hline+ & + & + & - & + & + & - & + & - & + & - & - & - & - & $(-)$ & & \\
\hline+ & + & + & + & + & + & + & + & + & + & + & + & $(-)$ & & & & \\
\hline+ & + & + & + & - & + & + & + & + & + & - & + & + & + & + & & \\
\hline+ & + & + & + & $(+)$ & + & + & + & + & + & $(+)$ & + & $(+)$ & & & & \\
\hline+ & + & + & + & + & + & + & + & + & + & + & & & & & & \\
\hline+ & + & + & + & + & + & + & $(+)$ & + & + & - & + & + & $(+)$ & & & \\
\hline+ & + & + & + & + & + & + & + & + & + & + & + & $(+)$ & - & $(+)$ & & \\
\hline+ & + & + & + & + & + & + & + & + & + & + & + & + & + & + & & \\
\hline+ & + & + & + & + & - & + & + & + & + & + & $(+)$ & + & + & + & & \\
\hline+ & + & + & + & + & + & + & + & + & + & + & & & & & & \\
\hline+ & + & + & + & + & + & + & + & + & + & + & + & + & + & & & \\
\hline+ & + & + & + & + & + & + & + & + & + & + & + & + & + & & & \\
\hline+ & + & + & + & + & & & & & & & & & & & & \\
\hline+ & + & + & & + & + & & & & & & & & & & & \\
\hline+ & + & + & + & & & & & & & & & & & & & \\
\hline+ & + & + & + & + & & & & & & & & & & & & \\
\hline+ & + & + & - & - & - & - & - & - & - & - & - & - & - & & & \\
\hline+ & + & + & - & - & - & - & - & - & - & - & - & - & - & & & \\
\hline+ & + & + & - & - & - & - & - & - & - & $(-)$ & - & $(-)$ & - & & & \\
\hline- & - & - & - & - & - & - & - & - & - & - & - & - & - & & & \\
\hline+ & - & - & - & - & - & - & - & - & - & - & - & - & - & & & \\
\hline+ & + & - & - & - & - & - & - & - & - & - & - & - & - & & & \\
\hline+ & + & - & - & - & - & - & - & - & - & - & - & - & - & & & \\
\hline- & - & - & - & - & - & - & - & - & - & - & - & - & - & & & \\
\hline
\end{tabular}




\section{High dose dapsone.}

Thirty-two patients who did not become negative under low dose DDS or had frequent reactional episodes were treated with high dose dapsone. Thirty of them were of lepromatous type, 2 borderline. All were placed on $600 \mathrm{mg}$ dapsone per week without build up. Eleven became negative within 1 year, 12 improved and 9 remained in statu quo after 1 year. Reactions were few and mild only, so that treatment was sustained.

\section{Acknowledgement}

I would like to thank my colleagues and all the staff at St. Thomas Hospital for their great interest in this work and their devoted cooperation: Professor Freerksen for his guidance, and the German Leprosy, Relief Association, Wuerzburg, for supplying us with the required drugs and for support and encouragement. 